\title{
Tranexamic acid for the treatment of heavy menstrual bleeding: efficacy and safety
}

This article was published in the following Dove Press journal:

International Journal of Women's Health

16 August 2012

Number of times this article has been viewed

\author{
Henri Leminen' \\ Ritva Hurskainen ${ }^{1,2}$ \\ 'Department of Obstetrics and \\ Gynecology, Hyvinkää Hospital, \\ Hyvinkää, Finland; ${ }^{2}$ Faculty of \\ Medicine, University of Helsinki, \\ Helsinki, Finland
}

Correspondence: Henri Leminen Hyvinkää Hospital, Sairaalankatu I, 05850 Hyvinkää, Finland

Tel +358 503739538

Fax +358 194587 2358

Email henri.leminen@hus.fi
Abstract: Tranexamic acid has proven to be an effective treatment for heavy menstrual bleeding (HMB). It reduces menstrual blood loss (MBL) by $26 \%-60 \%$ and is significantly more effective than placebo, nonsteroidal anti-inflammatory drugs, oral cyclical luteal phase progestins, or oral etamsylate, while the levonorgestrel-releasing intrauterine system reduces MBL more than tranexamic acid. Other treatments used for HMB are oral contraceptives, danazol, and surgical interventions (endometrial ablation and hysterectomy). Medical therapy is usually considered a first-line treatment for idiopathic HMB. Tranexamic acid significantly improves the quality of life of women treated for HMB. The recommended oral dosage is 3.9-4 g/day for 4-5 days starting from the first day of the menstrual cycle. Adverse effects are few and mainly mild. No evidence exists of an increase in the incidence of thrombotic events associated with its use. An active thromboembolic disease is a contraindication. In the US, a history of thrombosis or thromboembolism, or an intrinsic risk for thrombosis or thromboembolism are considered contraindications as well. This review focuses on the efficacy and safety of tranexamic acid in the treatment of idiopathic HMB. We searched for medical literature published in English on tranexamic acid from Ovid Medline, PubMed, and Cinahl. Additional references were identified from the reference lists of articles. Ovid Medline, PubMed, and Cinahl search terms were "tranexamic acid" and "menorrhagia" or "heavy menstrual bleeding." Searches were last updated on March 25, 2012. Studies with women receiving tranexamic acid for HMB were included; randomized controlled studies with a description of appropriate statistical methodology were preferred. Relevant data on the physiology of menstruation and the pharmacodynamics and pharmacokinetics of tranexamic acid are also included.

Keywords: tranexamic acid, heavy menstrual bleeding, menorrhagia

\section{Introduction}

Heavy menstrual bleeding (HMB) has a significant impact on many women's lives. ${ }^{1}$ The etiology is variable and can be either local, systemic, or iatrogenic. In half of all cases, no specific etiology is identified and HMB is called idiopathic. ${ }^{2}$ Heavy regular menstrual bleeding, or menorrhagia, is quantitatively defined as menstrual blood loss (MBL) of $80 \mathrm{~mL}$ or more per cycle., ${ }^{3,4}$ The definition has been widely adopted in clinical studies, while in practice, diagnosis is typically based on the subjective perception of MBL and its impact on quality of life (QOL).

There are a number of medical and surgical alternatives available for the treatment of HMB. These include the levonorgestrel-releasing intrauterine system (LNG-IUS), oral progestins, oral contraceptives, danazol, non-steroidal anti-inflammatory drugs (NSAIDs), and antifibrinolytic drugs, as well as endometrial ablation and hysterectomy. 
Many national guidelines (eg, in the UK and Finland) consider the medical alternatives a first-line treatment, especially for idiopathic HMB. Potential complications caused by surgical interventions can thus be avoided in many cases.

Tranexamic acid is an antifibrinolytic drug that has proven effective for HMB in clinical use. It has been used to treat HMB for over four decades in many European countries. In the US, however, tranexamic acid was not approved for the treatment of menorrhagia until 2009. ${ }^{5}$ The novel modifiedrelease formulation of oral tranexamic acid approved in the US was designed to increase patient tolerability by reducing the gastrointestinal adverse effects, which have previously been connected with the use of oral tranexamic acid. ${ }^{6}$

Long-term usage of tranexamic acid for HMB is likely, and thus, adverse events affecting safety are of particular importance. There has been concern about the possible increase of thromboembolic events with the use of tranexamic acid due to its mechanism of action. ${ }^{7,8}$ This review evaluates the use of tranexamic acid in the management of regular HMB in terms of efficacy, tolerability, dosage, and cost.

\section{Physiology of idiopathic heavy menstrual bleeding}

Menstruation is a highly synchronized physiological event that occurs in four steps. ${ }^{9}$ First is the premenstrual dissolution of the stromal extracellular matrix. It is dependent on the extracellular matrix-degrading effects of matrix metalloproteinases and changes in plasminogen activator inhibitors. In step two, endometrial vasoconstriction occurs. Prostaglandins and other prostanoids as well as endothelins are the key players during this phase. Step three involves secondary vasodilatation, vascular disruption, and tissue sloughing, which begins on the first day of menstruation. MBL is mainly (75\%) arterial, emerging from the spiral arterioles. ${ }^{10}$ During this phase, prostanoids, endothelins, matrix metalloproteinases, and plasminogen activators and inhibitors interact and participate. In step four, postmenstrual endometrial repair and regeneration begin. This involves thrombin effects on extracellular matrix degradation and postmenstrual angiogenesis. Angiogenesis is the key process in re-establishing endometrial vascular function. ${ }^{11}$ The two principal mediators of endometrial functioning are estrogen and progesterone, which exert their effects through cellular receptors. ${ }^{12}$

The pathogenesis of idiopathic heavy bleeding is poorly understood. Changes in the relationship between serum and local concentrations of vasoactive compounds, such as prostaglandins, endothelins, prostacyclins, and phospholipases, are associated with this bleeding problem. ${ }^{13,14}$
Also, endometrial fibrinolytic enzymes appear to have an important role in menstrual hemostasis, tissue shedding, and repair. Plasmin and plasminogen activator activity are increased in the menstrual fluid or in endometrial extracts in women with dysfunctional bleeding, suggesting increased fibrinolysis. ${ }^{15-17}$

\section{Pharmacodynamics and pharmacokinetics of tranexamic acid}

Tranexamic acid exerts its antifibrinolytic effect by reversibly blocking lysine binding sites on plasminogen, thus preventing plasmin from interacting with lysine residues on the fibrin polymer, causing subsequent fibrin degradation. ${ }^{6}$ In women with menorrhagia, fibrinolytic activity is high, likely due to high levels of plasmin and plasminogen activators from the endometrium. ${ }^{18}$ The majority of pharmacokinetic studies of tranexamic acid involve intravenous administration, ${ }^{19,20}$ and studies with oral formulations are with healthy males, but

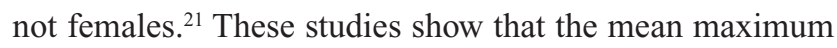
plasma concentration after $2 \mathrm{~g}$ of oral tranexamic acid was achieved 2-3 hours post-dose and was not affected by food. ${ }^{21}$ Tranexamic acid is minimally bound to plasma proteins (3\%) at therapeutic concentrations, which makes it highly binding to plasminogen. ${ }^{22}$ The main elimination route of tranexamic acid is via the kidneys, with an elimination half-life of about 2 hours. ${ }^{21}$ Caution is advised when administering tranexamic acid to patients with renal insufficiency.

\section{Therapeutic efficacy of tranexamic acid in heavy menstrual bleeding}

We identified 11 randomized controlled studies $(n=15-294)$ of variable design on oral tranexamic acid in the treatment of HMB (Table 1). ${ }^{23-33}$ Studies included women of reproductive age with regular HMB. Duration of the intervention varied from one to six cycles. MBL was assessed directly using a validated alkaline hematin $\operatorname{method}^{34}$ in seven studies, indirectly by pictorial blood loss assessment chart (PBAC) $)^{35,36}$ score in two studies, and by other indirect measurements in the remaining two studies. The primary outcome in all studies was the effect of treatment on MBL. Other outcome measures included duration of bleeding, number of sanitary napkins/tampons used, number of large stains, hemoglobin concentration, and QOL. Side effects/adverse effects were recorded to some extent in all studies. Tranexamic acid was compared with placebo, NSAIDs, oral progestins, LNG-IUS, oral hemostatic agent etamsylate, and intranasal desmopressin. The main results, discussed in detail below, are summarized in Table 1. 

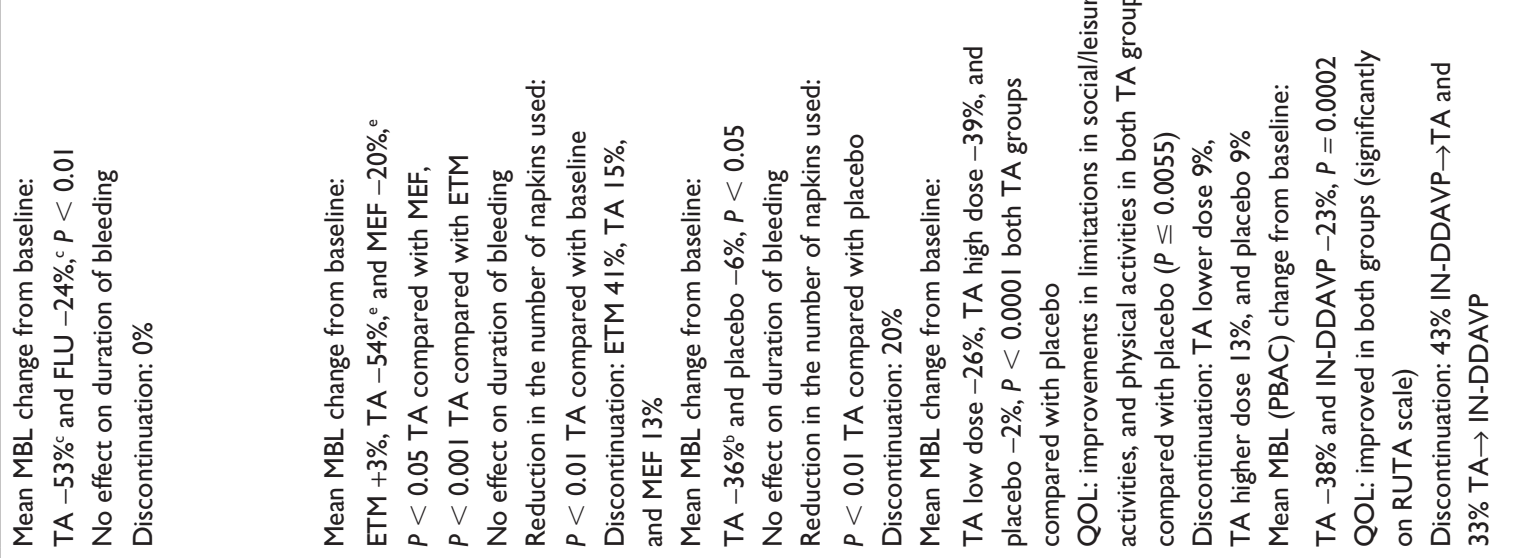

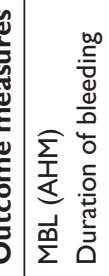
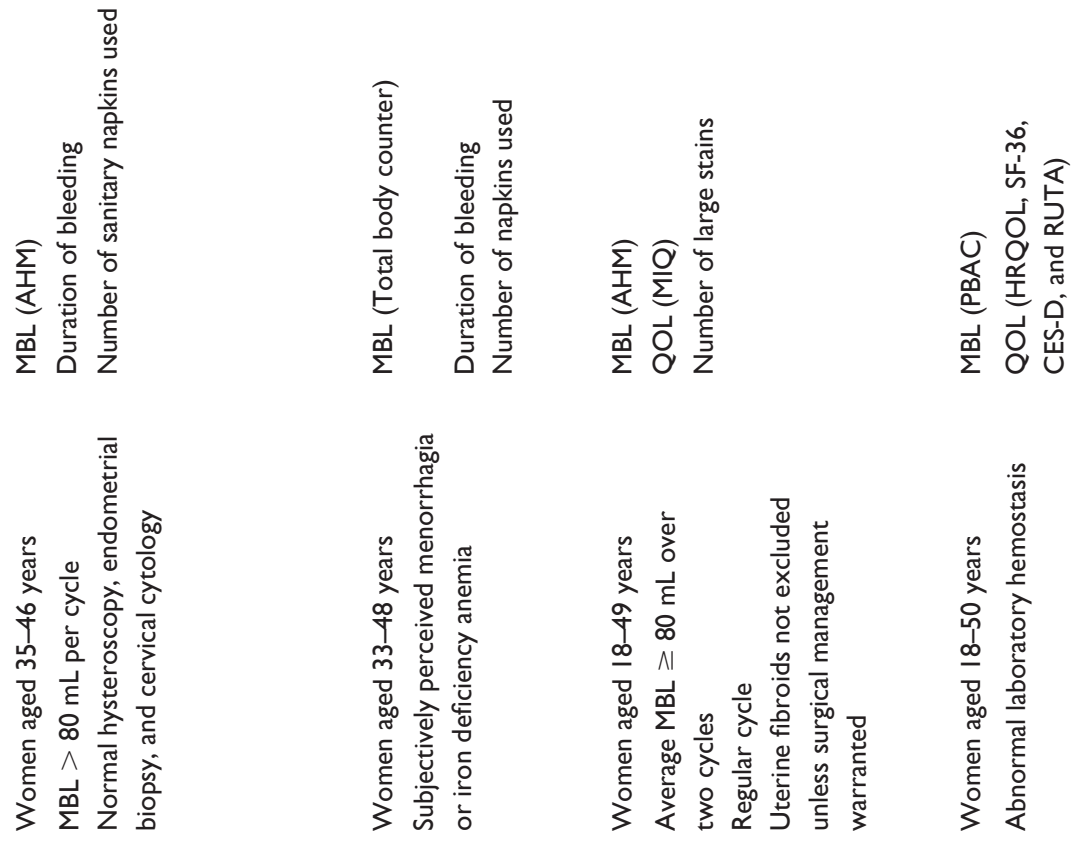

ลัก กั

ㅇํㅇำ
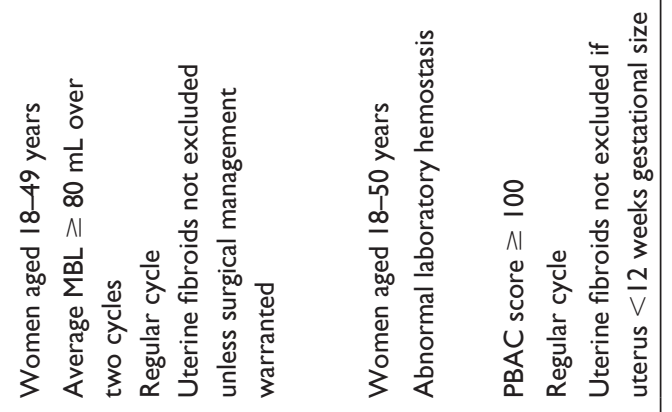

$=\underline{2}$ 느는

느ำเั่

เิ

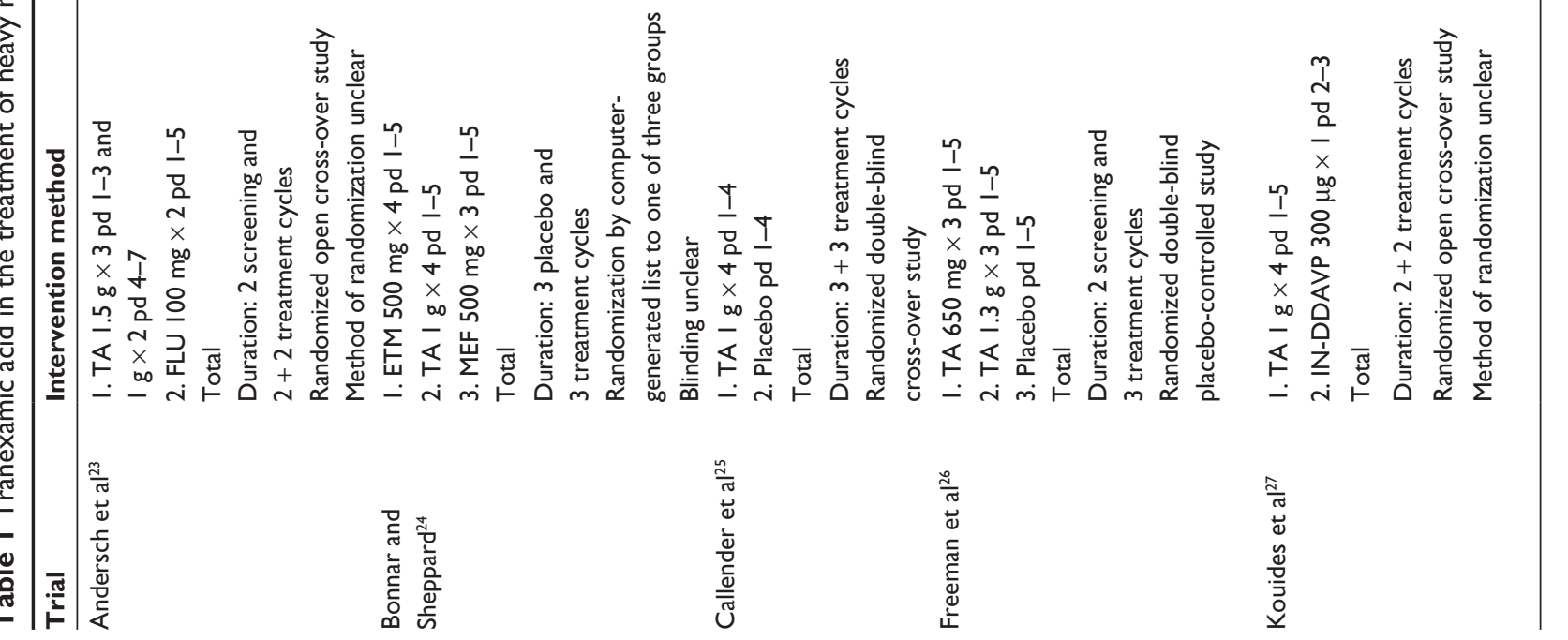




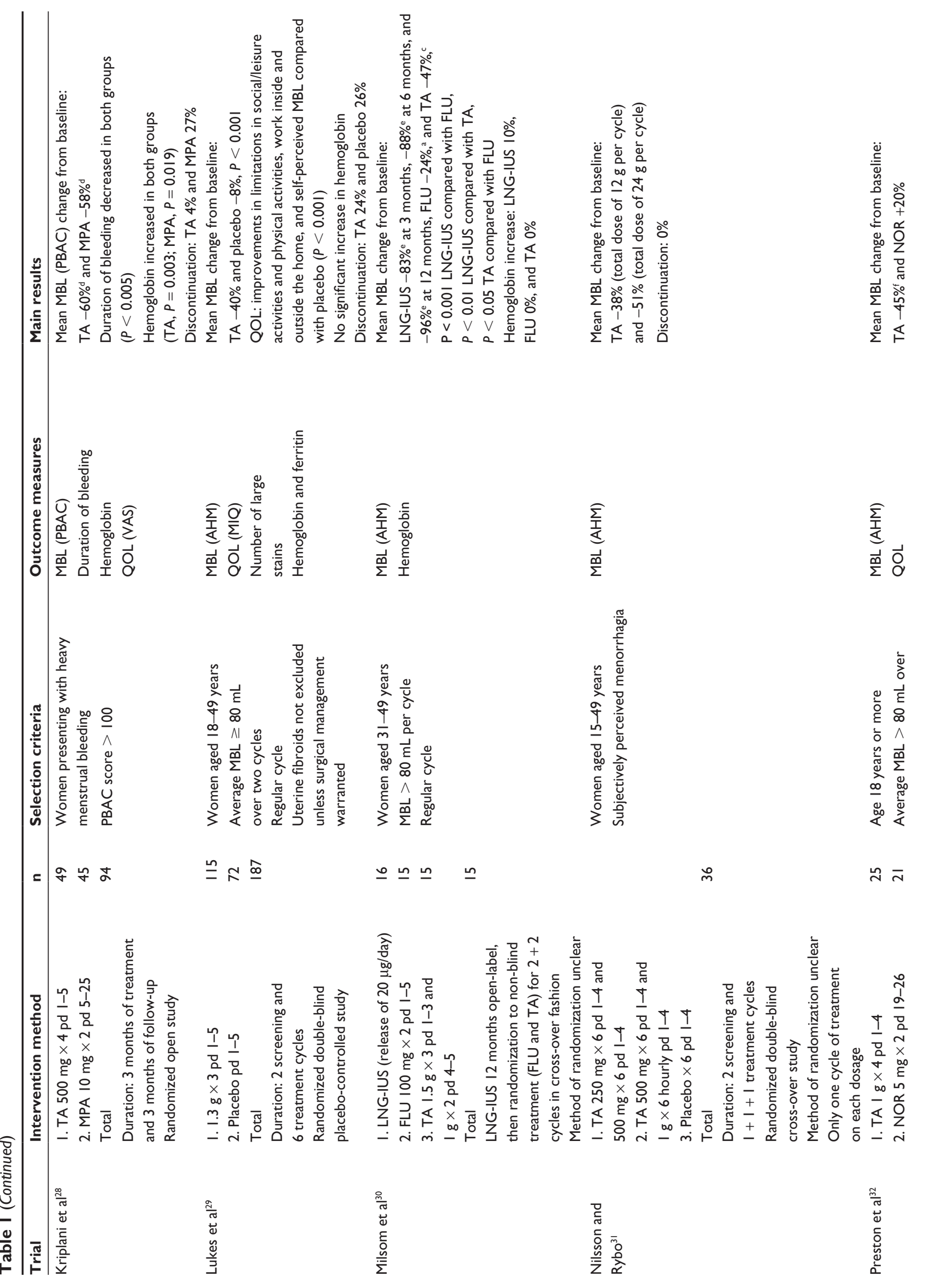




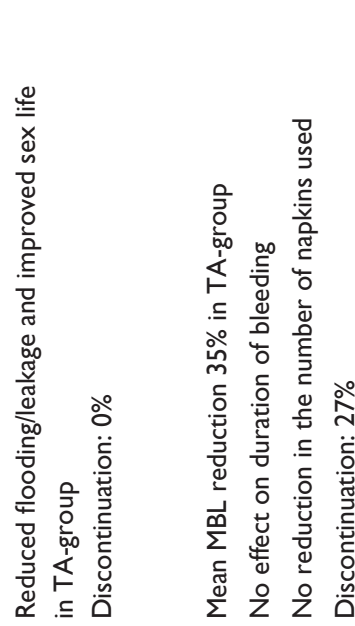

\section{Effect on menstrual blood loss}

Compared with the baseline, tranexamic acid 1.5-4.5 g/day taken for $4-7$ days per cycle reduced mean MBL by $26 \%-60 \%$ $(P<0.05)$ (five studies did not provide the $P$-value). ${ }^{23-33}$

In comparison with placebo, tranexamic acid reduced mean MBL from the baseline by $26 \%-50 \%$, while a $2 \%-8 \%$ reduction was seen in the placebo groups $(P<0.05)$ (two studies did not provide the $P$-value). ${ }^{25,26,29,31,33}$ In a randomized, placebo-controlled, double-blind study $(\mathrm{n}=187)$ by Lukes et al, ${ }^{29} \mathrm{MBL}$ declined to less than $80 \mathrm{~mL}$ (standard definition of heavy menstrual bleeding) in $43 \%$ of menstrual cycles in women receiving $3.9 \mathrm{~g}$ of tranexamic acid per day compared with $17 \%$ of cycles in women receiving placebo $(P<0.001)$. Furthermore, MBL was reduced at least $50 \mathrm{~mL}$ per cycle in $56 \%$ of cycles in the tranexamic acid group compared with $19 \%$ of cycles in the placebo group $(P<0.001)$. The percentage of cycles in which a patientperceived meaningful reduction in MBL of $36 \mathrm{~mL} / 22 \%{ }^{37}$ was achieved was greater in the tranexamic acid group (69\%) than in the placebo group $(17 \%)(P<0.001)$. The presence of uterine fibroids was not an exclusion criterion in this study unless the fibroids were of a sufficient number and size to warrant surgical treatment. Treatment with tranexamic acid was similarly effective in reducing mean MBL regardless of the presence of fibroids. ${ }^{29}$

Compared with NSAIDs, mean MBL was significantly more decreased with tranexamic acid than with flurbiprofen $200 \mathrm{mg} /$ day for 5 days $(P<0.05)^{23,30}$ or mefenamic acid $1.5 \mathrm{~g} /$ day for 5 days $(P<0.05) .{ }^{24}$ In the study by Bonnar and Sheppard, ${ }^{24}$ mean MBL declined to normal levels (less than $80 \mathrm{~mL}$ per cycle) in $100 \%$ of patients receiving tranexamic acid. The same study also compared tranexamic acid with an oral hemostatic agent, etamsylate $2 \mathrm{~g}$ /day for 5 days: etamsylate increased mean MBL by $3 \%$ relative to the reduction of $54 \%$ seen with tranexamic acid $(P<0.001) .{ }^{24}$

A study of an oral progestin and tranexamic acid showed that tranexamic acid $4 \mathrm{~g}$ /day for 4 days reduced mean MBL by $45 \%$, whereas norethisterone $10 \mathrm{mg} /$ day for 7 days during the luteal phase of the menstrual cycle increased MBL by $20 \%$. Mean MBL declined to normal in 56\% of women receiving tranexamic acid compared with $10 \%$ of those taking norethisterone. ${ }^{32}$ A randomized open-label study by Kriplani et a ${ }^{28}$ compared tranexamic acid $2 \mathrm{~g}$ /day for 5 days with medroxyprogesterone acetate (MPA) $20 \mathrm{mg} /$ day for 21 days starting from the fifth day of the menstrual cycle. Mean reduction in MBL, assessed using the PBAC score, was $60 \%$ in the tranexamic acid group and $58 \%$ in the MPA group. However, a lack of response was seen in $29 \%$ of women receiving MPA compared with only 
$6 \%$ of women receiving tranexamic acid $(P<0.003)$, and $27 \%$ of women in the MPA group discontinued because of bleeding problems and side effects compared with $4 \%$ in the tranexamic acid group $(P<0.002)$. Furthermore, during the six-month total study period, $18 \%$ of the MPA group underwent hysterectomy compared with $4 \%$ of the tranexamic acid group $(P<0.002){ }^{28}$

Compared with LNG-IUS, tranexamic acid was significantly less effective; the mean reduction of MBL after four cycles was $47 \%$ compared with $83 \%$ after three months of treatment with LNG-IUS $(P<0.01) .{ }^{30}$

The effect of intranasal desmopressin and tranexamic acid was studied in women with HMB and abnormal laboratory hemostasis in a randomized, open-label, cross-over trial $(\mathrm{n}=116)$. Women with confirmed menorrhagia (PBAC score $\geq 100$ ) had abnormal hemostasis in $73 \%$ of cases. Platelet aggregation and/or release abnormality was the most common abnormality (75\%), 11\% had subnormal coagulation factor level, 7\% Von Willebrand disease, and 7\% prolonged closure time. The mean decrease in PBAC score from the baseline was -105.7 for tranexamic acid $4 \mathrm{~g}$ /day for 5 days and -64.1 for intranasal desmopressin $300 \mu \mathrm{g}$ once per day for 2 days $(P=0.002) .{ }^{27}$

Treatment of heavy menstrual bleeding with tranexamic acid had no effect on duration of bleeding in most studies. ${ }^{23-25,33}$ The study comparing tranexamic acid with MPA, however, reported that the duration of bleeding decreased significantly compared with the baseline in both groups $(P<0.005) .{ }^{28}$ Number of sanitary napkins/tampons used was reported in three studies and decreased significantly with tranexamic acid treatment compared with the baseline or placebo $(P<0.01)$ in two of them. ${ }^{24,25}$ The study comparing tranexamic acid with MPA found a significant increase in mean hemoglobin concentration in both groups over the three-month intervention $(P=0.003$ and 0.019$),{ }^{28}$ while the other two studies reporting such data found no increase in hemoglobin during 4-6 cycles of treatment with tranexamic acid compared with the baseline. ${ }^{29,30}$

\section{Effect on quality of life}

Two randomized, placebo-controlled, double-blind studies used a validated disease-specific Menorrhagia Impact Questionnaire (MIQ) for assessing the change in QOL related to treatment of heavy menstrual bleeding with tranexamic acid. ${ }^{26,29}$ Freeman et $\mathrm{al}^{26}(\mathrm{n}=294)$ administered tranexamic acid for three cycles in doses of $1.95 \mathrm{~g} /$ day for 5 days compared with $3.9 \mathrm{~g} /$ day for 5 days and showed that mean MIQ scores for limitations in social or leisure activities and physical activities decreased significantly in both tranexamic acid groups compared with placebo $(P \leq 0.0055)$. Lukes et $\mathrm{al}^{29}$ used a dosage of $3.9 \mathrm{~g} /$ day for 5 days over six cycles $(\mathrm{n}=187)$. Similar results were obtained in their study; mean MIQ scores for limitations in social or leisure activities and physical activities, work outside or inside the home, and self-perceived MBL decreased significantly in the tranexamic acid group compared with placebo $(P<0.001)$, and the improvements were maintained throughout six cycles of treatment. ${ }^{29}$ In the study comparing tranexamic acid $4 \mathrm{~g}$ /day for 5 days with intranasal desmopressin, changes in QOL were assessed by four validated instruments (Health-Related Quality of Life, Short Form-36, Center for Epidemiologic Studies Depression Scale, and disease-specific modified Ruta Menorrhagia Severity Scale). While all instruments showed improvements in both treatment groups after two treatment cycles compared with the baseline, only Ruta Menorrhagia Severity scores decreased significantly, without differences between the groups $(P \leq 0.008) \cdot{ }^{27} \mathrm{~A}$ non-validated questionnaire using a five-point scale was utilized in a randomized, double-blind, placebo-controlled study $(n=46)$ comparing tranexamic acid $4 \mathrm{~g} /$ day for 4 days with norethisterone $10 \mathrm{mg} /$ day for 7 days during the luteal phase of the menstrual cycle over two cycles. A larger proportion of women in the tranexamic acid group than in the norethisterone group experienced improved sex life (46\% versus $15 \% ; P=0.029$ ) and reduced flooding/leakage ( $83 \%$ versus $45 \% ; P=0.008$ ) compared with the baseline or placebo. ${ }^{32}$ Improvements are also reported in a large openlabel uncontrolled study $(\mathrm{n}=849)$ investigating the effect of tranexamic acid 3-6 g/day for 3-4 days over three months on QOL. QOL was assessed using a self-developed questionnaire with a five-point scale. Concomitant medication was permitted, yet most women (84\%) used only tranexamic acid. After the third cycle, $81 \%$ were satisfied or very satisfied with the treatment, and $94 \%$ judged their MBL to be decreased or strongly decreased. Compared with the baseline, treatment with tranexamic acid during the third cycle reduced the proportion of women feeling a considerable degree of impairment during menstruation by more than $60 \%(P<0.0001)$, and increased the proportion of women feeling fit and active by $63 \%$ and those feeling no or little impairment in social activities during menstruation by $58 \%(P<0.0001){ }^{38}$

\section{Tolerability of tranexamic acid}

Freeman et $\mathrm{al}^{26}$ assessed the efficacy of a new oral formulation of tranexamic acid $1.95 \mathrm{~g} /$ day or $3.9 \mathrm{~g}$ /day for 5 days in a randomized, placebo-controlled, double-blind study $(\mathrm{n}=294)$ over three cycles. The majority of participants $(87 \%)$ reported 
adverse effects, with no significant differences between the three groups. Four women using tranexamic acid withdrew from the study because of adverse effects, which were considered definitely not or probably not related to study treatment. The most frequently reported adverse effects, occurring in $\geq 5 \%$ of tranexamic acid-treated women and at twice the rate of placebo-treated women, were viral upper respiratory infection $(7 \%-10 \%)$, fatigue $(4 \%-11 \%)$, musculoskeletal pain ( $5 \%-9 \%$ ), arthralgia (4\%-6\%), myalgia $(5 \%-4 \%)$, and nasal congestion ( $3 \%-7 \%)$. All but one of the higher percentages of these adverse effects were seen in the $1.95 \mathrm{~g} /$ day tranexamic acid group. ${ }^{26}$ The efficacy of a new oral formulation of tranexamic acid $3.9 \mathrm{~g}$ /day for 5 days over six cycles was studied in a randomized, placebo-controlled, double-blind trial $(n=187) .{ }^{29}$ The majority of adverse events were mild to moderate. No serious adverse events considered related to the treatment occurred. The most common adverse effects in both groups were menstrual discomfort/cramps (50\%-62\%), headache $(50 \%-56 \%)$, back pain (19\%-24\%), and nausea (15\%); no significant differences were present between the groups. ${ }^{29}$ In the study by Kouides et al, ${ }^{27} 7 \%$ of the women reported side effects in the tranexamic acid group and $8 \%$ in the intranasal desmopressin group. Headache was the most commonly reported side effect in both groups. Kriplani et $\mathrm{al}^{28}(\mathrm{n}=94)$ compared tranexamic acid $2 \mathrm{~g} /$ day for 5 days with MPA $20 \mathrm{mg} /$ day taken for 21 days. The duration of the intervention was three months. Side effects were reported in $16 \%$ of women in the tranexamic acid group compared with $33 \%$ of women in the MPA group. ${ }^{28}$

A long-term follow-up is available from an open-label single-arm study of 27 cycles $(n=723)$ of treatment with a new oral formulation of tranexamic acid $3.9 \mathrm{~g}$ /day for 5 days. The most commonly reported adverse effects were headache, menstrual discomfort, and back pain, and most of the adverse effects were mild to moderate in severity. Furthermore, adverse effects were largely considered unrelated to treatment with tranexamic acid. ${ }^{39}$

In the older studies, there was no significant increase in reported adverse effects with tranexamic acid when compared with placebo..$^{25,31,33}$ Furthermore, Lethaby et al ${ }^{40}$ have evaluated studies older than those discussed above in a Cochrane Review from the year 2000. They concluded that there was no significant increase in reported adverse events with tranexamic acid therapy compared with placebo or the other treatments studied. ${ }^{40}$

None of the studies, together including well over 2500 women, cited in this review have reported thromboembolic events with tranexamic acid treatment. Furthermore, in an observational population-based study over a 19 -year period and with 238,000 women-years of treatment with tranexamic acid, no reported increase occurred in the incidence of thromboembolic events. ${ }^{41,42}$ A more recent Swedish nested case-control study reported that the use of tranexamic acid for menorrhagia was associated with an increased risk for venous thromboembolism (adjusted odds ratio 3.20 [95\% CI $0.65-15.78]){ }^{43}$ However, the risk estimate did not reach statistical significance, and there were only three exposed cases using tranexamic acid compared with four exposed controls.

\section{Dosage of tranexamic acid in the treatment of heavy menstrual bleeding}

Orally administered tranexamic acid is available as $250 \mathrm{mg}$, $500 \mathrm{mg}$, or $650 \mathrm{mg}$ tablets and/or capsules and as a syrup containing $500 \mathrm{mg}$ in $5 \mathrm{~mL}$. In Europe, the recommended oral dosage of tranexamic acid for the treatment of menorrhagia is $1 \mathrm{~g}$ three times a day for up to 4 days. The dosage may be increased, but a total dose of $4 \mathrm{~g}$ per day should not be exceeded. Active thromboembolic disease, severe renal failure, and hypersensitivity to tranexamic acid are listed as contraindications. Caution is warranted when administering tranexamic acid to patients with a history of thromboembolic disease. ${ }^{22}$ In the US, the recommended oral dosage is $1.3 \mathrm{~g}$ three times a day for up to 5 days. Active thromboembolic disease, a history of thrombosis or thromboembolism, an intrinsic risk for thrombosis or thromboembolism, and hypersensitivity to tranexamic acid are contraindications. Caution is required in the concomitant use of hormonal oral contraceptives with tranexamic acid because the risk of thrombotic events may further increase. ${ }^{5}$

Dosage reductions are recommended for patients with renal impairment, according to serum creatinine concentration. ${ }^{5,22}$

Two randomized, double-blind, placebo-controlled studies compared different dosages of tranexamic acid in the treatment of menorrhagia. Freeman et $\mathrm{al}^{26}(\mathrm{n}=294)$ compared the efficacy of a new oral formulation of tranexamic acid $1.95 \mathrm{~g} /$ day for 5 days with $3.9 \mathrm{~g} /$ day for 5 days. Mean MBL reduction from the baseline was $26 \%$ in the $1.95 \mathrm{~g}$ /day group compared with $39 \%$ in the $3.9 \mathrm{~g} /$ day group. The mean reduction in MBL of more than $50 \mathrm{~mL}$ per cycle was achieved with the dosage of $3.9 \mathrm{~g} /$ day $(65 \mathrm{~mL})$, while the reduction was less in the $1.95 \mathrm{~g} /$ day group $(47 \mathrm{~mL})$. No significant differences emerged in the adverse effects recorded between the two groups. ${ }^{26}$ Nilsson and Rybo ${ }^{31}(n=36)$ compared tranexamic acid $1.5 \mathrm{~g} / \mathrm{day}, 3 \mathrm{~g} / \mathrm{day}$, and $6 \mathrm{~g} /$ day, each for 4 days. Mean MBL reduction was $38 \%$ with a total dose of $12 \mathrm{~g}$ per cycle 
and $51 \%$ with a total dose of 24 g per cycle. ${ }^{31}$ Both of these studies demonstrate a dose-response relationship in efficacy. The majority of treatment studies comparing tranexamic acid with either placebo or other medical therapies have used a tranexamic acid dosage of 4-4.5 g/day (Table 1).

\section{Cost of the treatment of heavy menstrual bleeding with tranexamic acid}

Health economic analyses of tranexamic acid in the treatment of HMB are few and do not adhere to recommended methodological guidelines. A retrospective, literature-based Norwegian study ${ }^{44}$ evaluated six medical treatments (NSAIDs, antifibrinolytic drugs, combined oral contraceptives, progestogens including LNG-IUS, transcervical resection, and hysterectomy). The only outcome measure was MBL, and the costs did not include complications, re-treatments, or follow-up time. The cost-effectiveness ratio favored medical treatments. Unfortunately, this study was based on a weak methodology and the results are unreliable. Moreover, the sole outcome measure gave limited information on the effectiveness of the treatments.

Recognizing the lack of health economic evidence on pharmaceutical treatments for HMB, the National Institute for Health and Clinical Excellence (NICE) guidelines for heavy menstrual bleeding developed a state-transition (Markov) model to assess the cost-effectiveness of four treatments (combined oral contraceptives, tranexamic acid, LNG-IUS, and NSAIDs). The analysis showed that compared with no treatment, tranexamic acid generated additional qualityadjusted life years (QALYs) at an additional cost. Compared with NSAIDs, tranexamic acid generated more QALYs at a lower cost, whereas compared with LNG-IUS, tranexamic acid generated fewer QALYs at a greater cost. ${ }^{45}$

\section{Conclusion}

Tranexamic acid 3.9-4 g/day for 4-5 days is an effective treatment for HMB. It significantly improves QOL relative to placebo or norethisterone, and is significantly more effective in reducing MBL than placebo, NSAIDs, oral cyclical luteal phase progestins, or etamsylate. The levonorgestrel-releasing intrauterine system reduces $\mathrm{MBL}$ significantly more than tranexamic acid. An oral progestin administered for 21 days per cycle might be as equally effective in reducing $\mathrm{MBL}$ as tranexamic acid, but a significantly larger proportion of women tend to discontinue the treatment due to side effects or lack of response. The presence of moderate-sized uterine fibroids does not seem to compromise the efficacy of tranexamic acid. Tranexamic acid is well tolerated and has a favorable safety profile. Adverse effects are few and they are mainly mild to moderate. The incidence of adverse gastrointestinal effects with the new oral formulation is comparable with that of placebo; even with the older preparations, no strong evidence supports an increase in adverse gastrointestinal effects with the use of tranexamic acid relative to placebo. Thromboembolic events have not been reported in treatment studies, and to date, data from population-based studies do not support the increase in incidence of venous thromboembolisms with the use of tranexamic acid. Treatment of HMB with tranexamic acid seems cost-effective compared with no treatment or NSAIDs, but not when compared with LNG-IUS. Tranexamic acid is non-hormonal, easy to use when needed, and exerts its effect fast. Potential complications caused by surgical procedures can be avoided by favoring medical therapy for HMB.

Studies comparing tranexamic acid with combined oral contraceptives or the combination of tranexamic acid and an NSAID for the treatment of heavy menstrual bleeding are lacking.

\section{Disclosure}

Henri Leminen reports no conflicts of interest. Ritva Hurskainen has received lecture fees from different pharmaceutical companies. No specific funding was obtained. The authors alone are responsible for the content and writing of this paper.

\section{References}

1. Liu Z, Doan QV, Blumenthal P, Dubois RW. A systematic review evaluating health-related quality of life, work impairment, and healthcare costs and utilization in abnormal uterine bleeding. Value Health. 2007;10(3):183-194.

2. Rees M. Menorrhagia. Br Med J (Clin Res Ed). 1987;294(6574): 759-762.

3. Hallberg L, Högdahl AM, Nilsson L, Rybo G. Menstrual blood lossa population study. Variation at different ages and attempts to define normality. Acta Obstet Gynecol Scand. 1966;45(3):320-351.

4. Wyatt KM, Dimmock PW, Walker TJ, O'Brien PM. Determination of total menstrual blood loss. Fertil Steril. 2001;76(1):125-131.

5. http://www.fda.gov [homepage on the Internet]. US Food and Drug Administration. Drugs@FDA: Lysteda (tranexamic acid) label information. Available from: http://www.accessdata.fda.gov/drugsatfda_ docs/label/2011/022430s002lbl.pdf. Accessed March 19, 2012.

6. Wellington $\mathrm{K}$, Wagstaff AJ. Tranexamic acid: A review of its use in the management of menorrhagia. Drugs. 2003;63(13):1417-1433.

7. Taparia M, Cordingley FT, Leahy MF. Pulmonary embolism associated with tranexamic acid in severe acquired haemophilia. Eur J Haematol. 2002;68(5):307-309.

8. Woo KS, Tse LK, Woo JL, Vallance-Owen J. Massive pulmonary thromboembolism after tranexamic acid antifibrinolytic therapy. $\mathrm{Br} J$ Clin Pract. 1989;43(12):465-466.

9. Dawood M, Huang J. Uterine vascular function and menstruation. Curr Obstet Gynaecol. 1998;8(2):66-72.

10. Markee JE. Morphological basis for menstrual bleeding; relation of regression to the initiation of bleeding. Bull NYAcad Med. 1948;24(4): 253-268. 
11. Rogers PA, Lederman F, Taylor N. Endometrial microvascular growth in normal and dysfunctional states. Hum Reprod Update. 1998;4(5): 503-508.

12. Ferenczy A, Bertrand G, Gelfand MM. Proliferation kinetics of human endometrium during the normal menstrual cycle. Am J Obstet Gynecol. 1979;133(8):859-867.

13. Smith SK, Abel MH, Kelly RW, Baird DT. Prostaglandin synthesis in the endometrium of women with ovular dysfunctional uterine bleeding. Br J Obstet Gynaecol. 1981;88(4):434-442.

14. Wang IY, Fraser IS, Barsamian SP, et al. Endometrial lysosomal enzyme activity in ovulatory dysfunctional uterine bleeding, IUCD users and post-partum women. Mol Hum Reprod. 2000;6(3):258-263.

15. Rybo G. Plasminogen activators in the endometrium. II. Clinical aspects. Variation in the concentration of plasminogen activators during the menstrual cycle and its relation to menstrual blood loss. Acta Obstet Gynecol Scand. 1966;45(4):429-450.

16. Hefnawi F, Saleh A, Kandil O, El-Sheikha Z, Hassanein M, Askalani H Fibrinolytic activity of menstrual blood in normal and menorrhagic women and in women wearing the lippes loop and the cu-T (200). Int J Gynaecol Obstet. 1979;16(5):400-407.

17. Gleeson NC, Buggy F, Sheppard BL, Bonnar J. The effect of tranexamic acid on measured menstrual loss and endometrial fibrinolytic enzymes in dysfunctional uterine bleeding. Acta Obstet Gynecol Scand. 1994 73(3):274-277.

18. Dockeray CJ, Sheppard BL, Daly L, Bonnar J. The fibrinolytic enzyme system in normal menstruation and excessive uterine bleeding and the effect of tranexamic acid. Eur J Obstet Gynecol Reprod Biol. 1987; 24(4):309-318.

19. Benoni G, Björkman S, Fredin H. Application of pharmacokinetic data from healthy volunteers for the prediction of plasma concentrations of tranexamic acid in surgical patients. Clin Drug Invest. 1995;10(5): 280-287.

20. Eriksson O, Kjellman H, Pilbrant A, Schannong M. Pharmacokinetics of tranexamic acid after intravenous administration to normal volunteers. Eur J Clin Pharmacol. 1974;7(5):375-380.

21. Pilbrant A, Schannong M, Vessman J. Pharmacokinetics and bioavailability of tranexamic acid. Eur J Clin Pharmacol. 1981;20(1): 65-72.

22. http://www.ema.europa.eu [homepage on the Internet]. European Medicines Agency. Committee for proprietary medicinal products (CPMP) opinion following an article 10 referral: CYKLO-f (tranexamic acid). Available from: http://www.ema.europa.eu/ema/index.jsp?curl=pages/ medicines/human/referrals/Cyklo-f/human_referral_000097. jsp\&mid=WC0b01ac0580024e9a\#. Accessed March 19, 2012.

23. Andersch B, Milsom I, Rybo G. An objective evaluation of flurbiprofen and tranexamic acid in the treatment of idiopathic menorrhagia. Acta Obstet Gynecol Scand. 1988;67(7):645-648.

24. Bonnar J, Sheppard BL. Treatment of menorrhagia during menstruation: Randomised controlled trial of ethamsylate, mefenamic acid, and tranexamic acid. BMJ. 1996;313(7057):579-582.

25. Callender ST, Warner GT, Cope E. Treatment of menorrhagia with tranexamic acid. A double-blind trial. Br Med J. 1970;4(5729): 214-216.

26. Freeman EW, Lukes A, VanDrie D, Mabey RG, Gersten J, Adomako TL. A dose-response study of a novel, oral tranexamic formulation for heavy menstrual bleeding. Am J Obstet Gynecol. 2011;205(4): 319.e1-319.e7.

International Journal of Women's Health

\section{Publish your work in this journal}

The International Journal of Women's Health is an international, peerreviewed open-access journal publishing original research, reports, reviews and commentaries on all aspects of women's healthcare including gynecology, obstetrics, and breast cancer. Subject areas include: Chronic conditions (migraine headaches, arthritis, osteoporosis);
27. Kouides PA, Byams VR, Philipp CS, et al. Multisite management study of menorrhagia with abnormal laboratory haemostasis: A prospective crossover study of intranasal desmopressin and oral tranexamic acid. Br J Haematol. 2009;145(2):212-220.

28. Kriplani A, Kulshrestha V, Agarwal N, Diwakar S. Role of tranexamic acid in management of dysfunctional uterine bleeding in comparison with medroxyprogesterone acetate. J Obstet Gynaecol. 2006;26(7): 673-678.

29. Lukes AS, Moore KA, Muse KN, et al. Tranexamic acid treatment for heavy menstrual bleeding: A randomized controlled trial. Obstet Gynecol. 2010;116(4):865-875.

30. Milsom I, Andersson K, Andersch B, Rybo G. A comparison of flurbiprofen, tranexamic acid, and a levonorgestrel-releasing intrauterine contraceptive device in the treatment of idiopathic menorrhagia. Am J Obstet Gynecol. 1991;164(3):879-883.

31. Nilsson L, Rybo G. Treatment of menorrhagia with an antifibrinolytic agent, tranexamic acid (AMCA): A double blind investigation. Acta Obstet Gynecol Scand. 1967;46(4):572-580.

32. Preston JT, Cameron IT, Adams EJ, Smith SK. Comparative study of tranexamic acid and norethisterone in the treatment of ovulatory menorrhagia. Br J Obstet Gynaecol. 1995;102(5):401-406.

33. Vermylen J, Verhaegen-Declercq ML, Verstraete M, Fierens F. A double blind study of the effect of tranexamic acid in essential menorrhagia. Thromb Diath Haemorrh. 1968;20(3):583-587.

34. Hallberg L, Nilsson L. Determination of menstrual blood loss. Scand J Clin Lab Invest. 1964;16:244-248.

35. Higham JM, O’Brien PM, Shaw RW. Assessment of menstrual blood loss using a pictorial chart. Br J Obstet Gynaecol. 1990;97(8):734-739.

36. Janssen CA, Scholten PC, Heintz AP. A simple visual assessment technique to discriminate between menorrhagia and normal menstrual blood loss. Obstet Gynecol. 1995;85(6):977-982.

37. Lukes AS, Muse K, Richter HE, Moore KA, Patrick DL. Estimating a meaningful reduction in menstrual blood loss for women with heavy menstrual bleeding. Curr Med Res Opin. 2010;26(11):2673-2678.

38. Winkler UH. The effect of tranexamic acid on the quality of life of women with heavy menstrual bleeding. Eur J Obstet Gynecol Reprod Biol. 2001;99(2):238-243.

39. Muse K, Lukes AS, Gersten J, Waldbaum A, Mabey RG, Trott E. Long-term evaluation of safety and health-related quality of life in women with heavy menstrual bleeding treated with oral tranexamic acid. Womens Health (Lond Engl). 2011;7(6):699-707.

40. Lethaby A, Farquhar C, Cooke I. Antifibrinolytics for heavy menstrual bleeding. Cochrane Database Syst Rev. 2000;4:CD000249.

41. Berntorp E, Follrud C, Lethagen S. No increased risk of venous thrombosis in women taking tranexamic acid. Thromb Haemost. 2001; 86(2):714-715.

42. Rybo G. Tranexamic acid therapy: Effective treatment in heavy menstrual bleeding. Clinical update on safety. Therapeutic Advances. 1991;4:1-8.

43. Sundström A, Seaman H, Kieler H, Alfredsson L. The risk of venous thromboembolism associated with the use of tranexamic acid and other drugs used to treat menorrhagia: A case-control study using the General Practice Research Database. BJOG. 2009;116(1):91-97.

44. Kirschner R. A cost-benefit analysis of different therapeutic methods in menorrhagia. Tidsskr Nor Laegeforen. 1995;115(5):618-621.

45. National Collaborating Centre for Women's and Children's Health (UK). Heavy Menstrual Bleeding. London: RCOG Press; 2007.

\section{Dovepress}

Endocrine and autoimmune syndromes; Sexual and reproductive health; Psychological and psychosocial conditions. The manuscript management system is completely online and includes a very quick and fair peer-review system. Visit http://www.dovepress.com/ testimonials.php to read real quotes from published authors. 